\title{
Simulation as an Instrument for Research of Driver-vehicle Interaction
}

\author{
Kristián Čulík ${ }^{1, *}$, Alica Kalašová ${ }^{1}$, and Simona Kubíková ${ }^{1}$ \\ ${ }^{1}$ University of Žilina, Faculty of Operation and Economics of Transport and Communications, \\ Department of Road and Urban Transport, Univerzitná 8215/1, 01026 Žilina, Slovakia
}

\begin{abstract}
This report describes opportunities for using driving simulators for research of driver-vehicle interaction. We have focused on examples of the using of the current equipment of the University Science Park of University of Žilina. Laboratory was built for research of driver-vehicle interaction. It's also important to give examples of evaluation after several measurements. The SNA - 211 REN driving simulator was used for each experimental measurement. It was necessary to use some additional equipment, because the driving simulator was used only for simulation. During simulations, drivers have been performing tasks connected with vehicle driving. Driver's eye tracking in specific conditions was also important part of our research. We have tested the behaviour of drivers when they have used mobile phones for texting and GPS device with touchscreen.
\end{abstract}

\section{Introduction}

The rising pace of life raises the claim for psychological resistance of a person and that affects human thinking and behaviour. This is always reflected during driving the vehicle. From the view of road transport, it is necessary to research the driver-vehicle interaction, because its results can help to increase safety of road traffic.

Driving simulators are devices, which can be used as a safe and practical instrument for research of driver-vehicle interaction under laboratory conditions. Nowadays the driver is still fully responsible for his vehicle and its safety systems, but subjects for research are not only the parts of the vehicle. We can also simulated different influences of road infrastructure and environment.

Therefore, we have done series of measurements with many drivers with using training driving simulator SNA - 211 REN. This device isn't research driving simulator as we need, but it can simulate some basic traffic situations. Measurements were done thanks to external recording and using additional equipment. Software of the simulator is not editable. Drivers had predefined specific tasks in all parts of research. This task has included driving through the narrow areas, texting during freeway ride, setting the GPS navigation device etc.

\footnotetext{
* Corresponding author: kristian.culik@fpedas.uniza.sk
} 


\section{Driver-vehicle interaction}

Road traffic, especially motor transport as its most important part, can be defined as a complex system of many partial events and phenomena. They together affect driving individual vehicles and all signs that characterize transport. Significant part of partial transport events is very variable and their appearance is random. Therefore, the transport can be attributed to stochastic character and its each partial events can be considered as random variables in mathematical meaning. If we evaluate the transport from the view of fluency, safety and economy, its complex effect is depended on the quality of certain factors, which can be incorporated into three basic groups in system human - vehicle environment $[1,2]$.

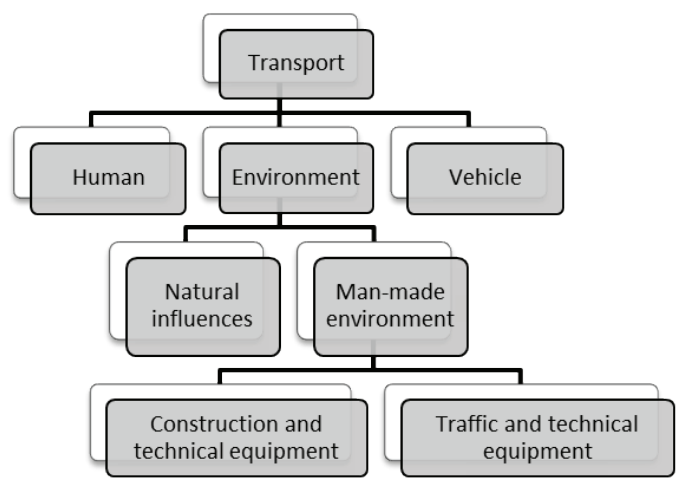

Fig. 1. Scheme of the transport system. Source: [1]

\subsection{Driver's behaviour}

Driver's behaviour is a process with two levels. First, it is unconscious level, which includes automatic activities during driving. Second level is conscious, when driver starts automatic activities after changing the driving conditions and also decides about the most suitable action. Vehicle driving is very difficult and complex activity and it requires permanent attention and reactions to stimuli [1-3].

From the view of traffic psychology, it's possible to express the driver behaviour during ride with following equation (1) respective function:

$$
R=f(S-O)
$$

where: $\quad \mathrm{R}$ - driver's behaviour (reactions)

$\mathrm{S}$ - perceived and acting stimuli on the driver

O - driver's personal characteristics

\subsection{Significance of driver-vehicle interaction}

Pyramid in the figure 2 shows approximate ratios between specific levels of cases. This cases result from interaction between road users - it's C. Hydén's pyramid of interaction. From the picture is obvious, that a small portion of the conflicts may end up in an accident. Specifically regarding the consideration of the potential conflicts or near accidents, complementary sources of accident records are not considered, but this task is quite important [4]. 


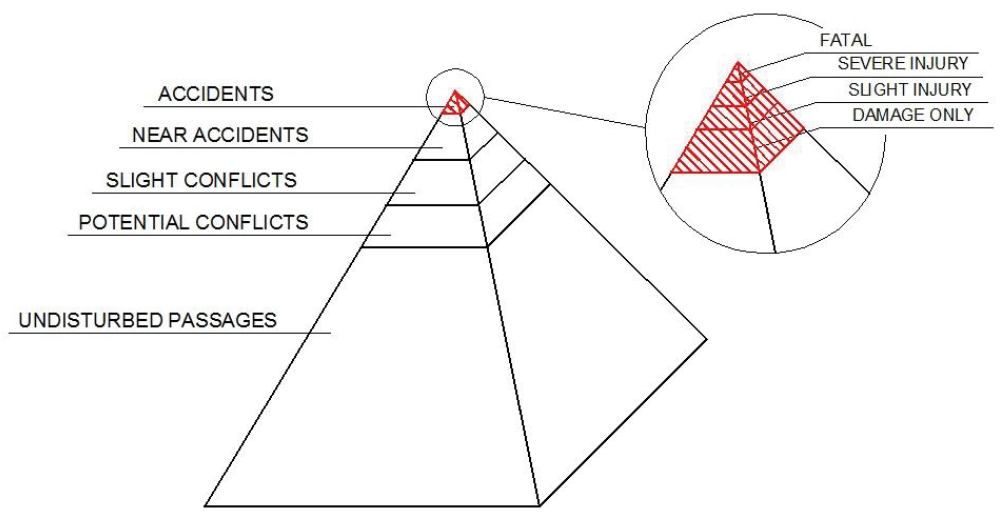

Fig. 2. Pyramid of interaction among road users. Source: [4]

From the picture is obvious, that is only possible to measure conflicts on the top of the pyramid. Under the peak of the pyramid, there is a lot of different kind of conflicts between vehicles respectively road users. These conflicts are not simply defined, because a physical accident isn't happen. Number of these conflicts we can estimate with for example from subjective opinions expressed in questionnaire. Better method for research of driver's behaviour is to measure their actions and trajectory of their vehicles in safe conditions. Ideal device for this kind of research is driving simulator. With high accuracy, we can record distance between vehicles, distance between vehicle and obstacle and so on [3-5].

\section{Simulations for research of driver-vehicle interaction}

The driving simulator is simply defined as a device which is used for simulation of driving a road vehicle in environment, which is similar to real conditions in road traffic. Light driving simulators (devices, that do not include the whole car, but only some parts of cockpit) are effective instrument for driver training, but they usage is more important in research of human-machine (driver-vehicle) interaction $[5,6]$.

Nowadays only a little attention is given to the research of driver-vehicle interaction in the Slovak republic. University of Žilina also does not have a full-valued research driving simulator, which could be used for measurements and also capable to automatically evaluate the impact of the vehicle and its components to the driver.

At the University Science Park of University of Žilina, there is a training driving simulator SNA - 211 REN (fig. 3) for research in the field of road transport. It is a device, which simulates driving a lorry (Renault Midlum) and a truck (Renault Magnum) with trailer or tank trailer.

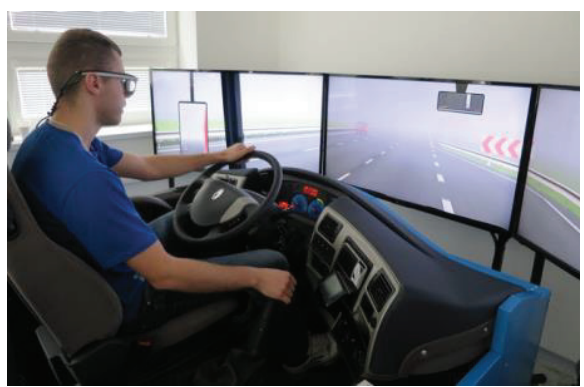

Fig. 3. The cabin of training driving simulator SNA - 211 REN. Source: authors 


\subsection{Equipment, drivers and preparation}

The training driving simulator SNA - 211 REN can only simulate the real conditions on the roads, but it's necessary to use additional devices to record the process of driving in virtual environment and also tools, which are necessary for particular driver's task. It is very important to find the ways for easy measurements and collecting the output data. The training driving simulator, which was used for our experiments, cannot provide recording of input or output data. For driver's eye tracking, we have used SMI Eye Tracking Glasses 2 connected with recording device - smartphone Samsung. Other parts of research have needed digital video camera.

For specific experiments, we have chosen people from the same age category 23-26 years. We hadn't established special requirements to the drivers before the drivers were chosen. It was very important to provide the simulation in undisturbed conditions, so the instructions for the driver were always very simple. It guaranteed that the results were minimally affected.

\subsection{Quantification of driver's skills during driving in slalom}

First task for drivers included driving the vehicle in slalom. This task is evaluated in complex graph in figure 4. Black line in the graph connects the absolute sums of time, which was needed to accomplish the tasks. The values in seconds are for all drivers together. It's obvious that the value of time is rapidly improving with experience and accustoming the driver to the virtual vehicle. Histograms of driver's mistakes are irregular and also decreasing. Left columns show the conflicts with traffic cones, right are numbers of unwanted exits from asphalt lane. Virtual environment of the simulator had these settings during the simulation: adhesion $90 \%$ asphalt, load $0 \%$, visibility - day.

Faults and summary time of task

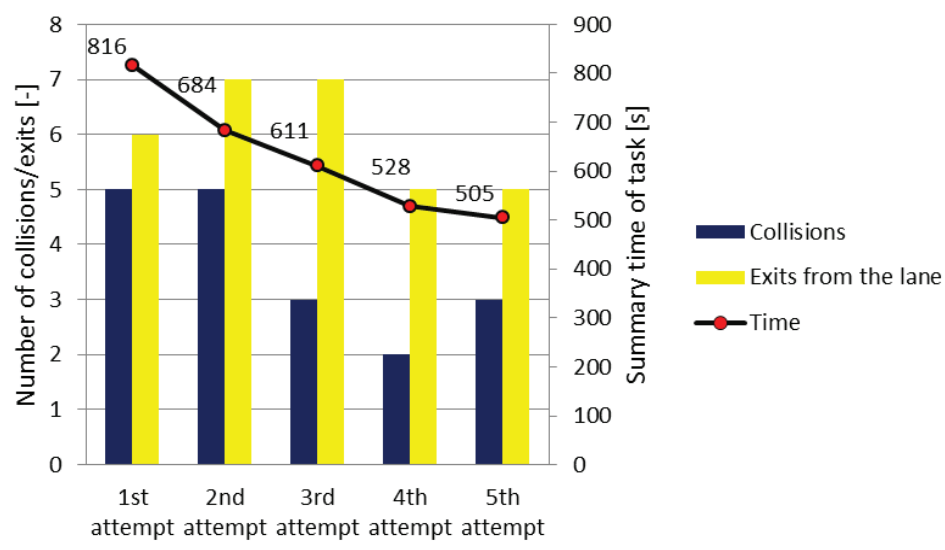

Fig. 4. Summary graph of driver's mistakes and slalom time. Source: authors

During the data processing, we made two groups of drivers. In the first group was faster half of drivers and in the second the remaining slower drivers. From the more detailed evaluation of changes in average speed, it's interesting that the growth of the average speed of the faster group has a concave shape and the slower group has a convex graph. More experienced drivers can drive with higher speed and their accustoming to the vehicle is faster. 


\subsection{Driving through the narrow areas}

In the next part of our research, we have decided to test how drivers can drive through the narrow areas, because the SNA - 211 REN simulates the truck driving, so the vehicle is quite bigger than personal car. Simulator has one specific scene - "Narrow areas", which is ideal for this task. It includes road circuit with five points - at each are two walls and between them is narrow area only for one vehicle with only little allowance. The vehicle, which is used in this simulation, is Renault Midlum.

In this task, every driver has drove through the narrow areas as fast as he can, but without contact with any wall. Driver has driven the circuit five times, so every driver has passed 25 narrow points.

For the recording time and vehicle speed, we have used external video camera recording. Outputs of record are these data:

- start time, time in half of circuit, finish time

- distances

- minimal speed in narrow area (for every point)

Minimal speed in narrow area was read with accuracy $1 \mathrm{~km} / \mathrm{h}$ and it is minimal value from all showed values during driving in the narrow area. Accuracy of times is 0,04 second, because the frame rate is 25 frames per second. For the evaluation, we have made partially automatic form, which include driving time, travelled distance, calculated section speed, as well as number of fails, which were made by drivers during this task.

Faults and average vehicle speed of the task

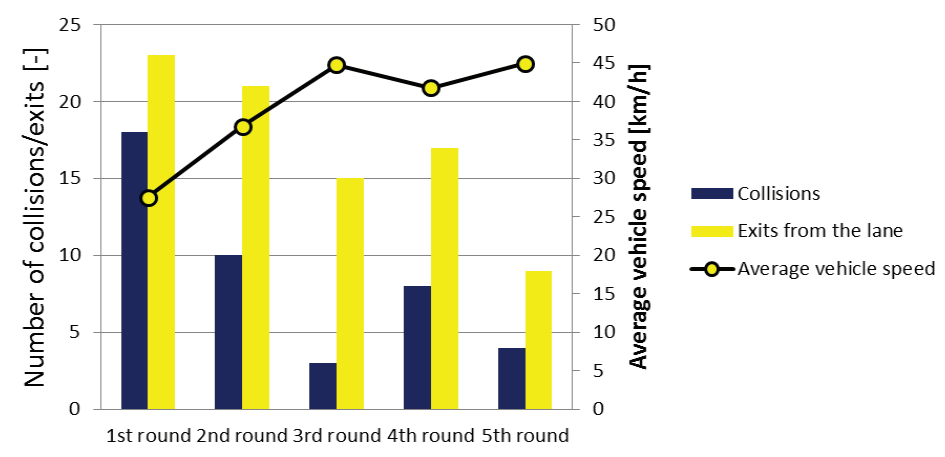

Fig. 5. Summary graph of driver fails and vehicle speed. Source: authors

Graph in the figure 5 shows that the sum of failures has decrease tendency, with the exception of the fourth attempt. With the successful passing the narrow areas drivers has increased their vehicle speed and they was also less concentrated. It turned out during four rounds, where faults have increased.

Other option for evaluation of driver's behaviour during ride with lorry is comparison of their achieved results. Columns in the next graph (fig. 6) show all faults during this task collisions with walls and also number of escapes from the lane. Vehicle speed is average speed of all drivers and vehicle speed in narrow area is an average value from all minimal speeds. 


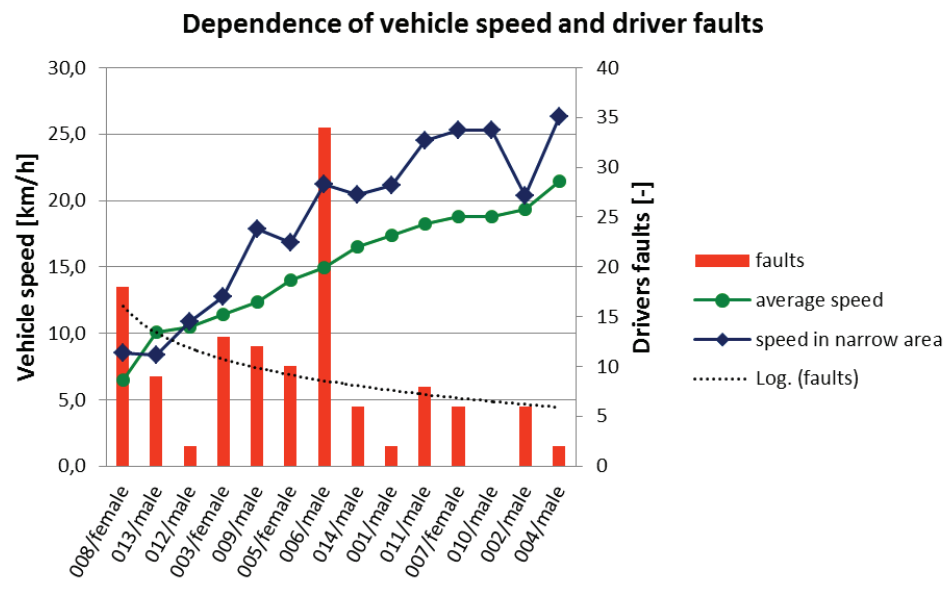

Fig. 6. Graph of vehicle speed, speed in narrow areas and driver's faults. Source: authors

\subsection{Reaction time}

Simulation for this task had a predetermined set of obstacles, which are generated in certain distance from the vehicle during driving. SNA - 211 REN has summer and winter alternative of this scene. We have chosen the winter scene, because the visibility of obstacles is lower, so the task can be harder for driver. Obstacles imitate the fall of tree, wild animal running across the road etc.

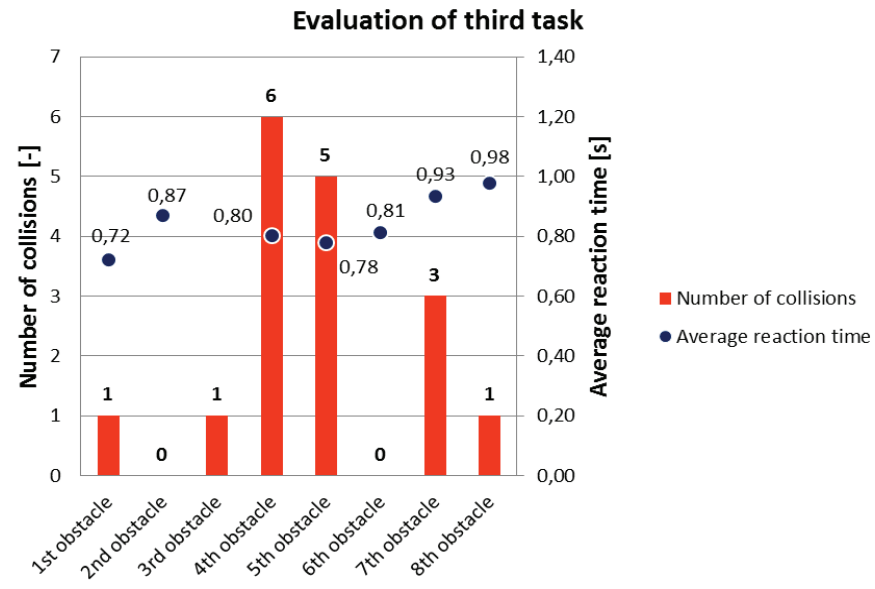

Fig. 7. Graph of average reaction times and numbers of collisions. Source: authors

From the graphical representation of task results in the figure 7 is clear that six drivers couldn't prevent collision with sixth obstacle. Average reaction time was only 0,80 second, so the drivers were concentrated, but only one driver has stopped in front of the obstacle. Video analysis showed, that this obstacle in this scene (falling tree) is starting relatively late. The position of the vehicle is so close to the obstacle, that it is impossible to stop the vehicle from higher speed. We wanted to measure reaction times, so bypassing the obstacle was forbidden.

\subsection{Eye tracking}


Simulation of driving has many advantages. One of the biggest is possibility to research behaviour, which is forbidden in road traffic by law, for example driving under the influence of alcohol, phoning at the wheel etc. Driving simulators give us the opportunity to drive virtual vehicle in safe conditions, so other disturbing elements are not dangerous. So it's also possible to test the influence of radio, air condition, on board systems and so on.

For this part of our research, we have chosen freeway simulation scene, because shifting the eight gears on the hilly terrain can be difficult and it requires a lot of attention. On the freeway, driver must only check only position on the lane and vehicle speed. During the eye tracking every driver had a certain distance for free ride and then they have been doing two specific tasks during driving:

- first task was writing an SMS on the smartphone

- second task was setting target destination on a GPS device with touchscreen.

Output of the eye tracking glasses is video format avi, which is necessary to next analysis with accuracy 10 points per second. We have used time stamps function in video editor. Marking times, when the driver change the point of view, is the most effective and accurate method of evaluation. After creating all time stamps, we have exported them to the table editor.

Table 1. Eye tracking results of specific driver. Source: authors

\begin{tabular}{|c|c|c|c|c|}
\hline Measurement: & E-04 & Scene: & \multicolumn{2}{|c|}{ freeway } \\
\hline Date: & 12.4 .2017 & Load & \multicolumn{2}{|c|}{$100 \%$} \\
\hline Driver: & 009/male & Adhesion: & \multicolumn{2}{|c|}{$90 \%$ asphalt } \\
\hline Driv. licence: & $\mathrm{B}$ & Visibility & \multicolumn{2}{|c|}{ mist } \\
\hline Value & \multicolumn{2}{|c|}{ Value meaning } & Time & Ratio \\
\hline 1 & \multicolumn{2}{|c|}{ view in field of view } & 164.8 & $61.8 \%$ \\
\hline 2 & \multicolumn{2}{|c|}{ view of dashboard and cabin } & 44.1 & $16.5 \%$ \\
\hline 3 & \multicolumn{2}{|c|}{ view of mobile phone/GPS } & 57.9 & $21.7 \%$ \\
\hline & & $\sum$ & 266.9 & $100.0 \%$ \\
\hline
\end{tabular}

Complex graphical evaluation of the tasks is more important than individual numerical results. Figure 8 shows pie chart with average total time of viewing the specific areas during free ride. During this part, the drivers were fully concentrated. They have looked to the road and environment $81 \%$ of the time and to the cabin and its equipment remaining time $(18 \%)$

\section{Average direction of view during free ride}

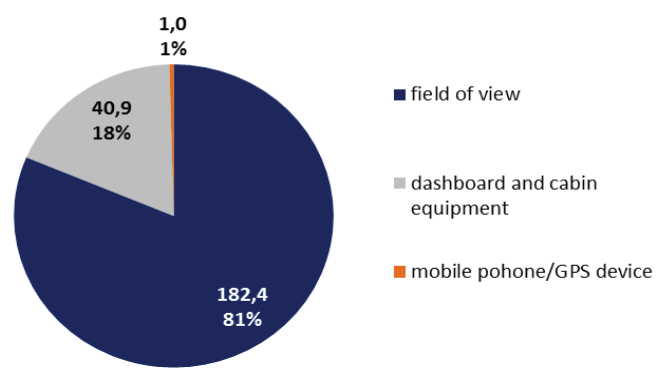

Fig. 8. Pie chart of results from eye tracking during free ride. Source: authors

However, eye tracking results are more important, when tested driver has been doing some other task during his drive. Average percentage ratios of driver's view are showed in pie charts in the figure 9. 

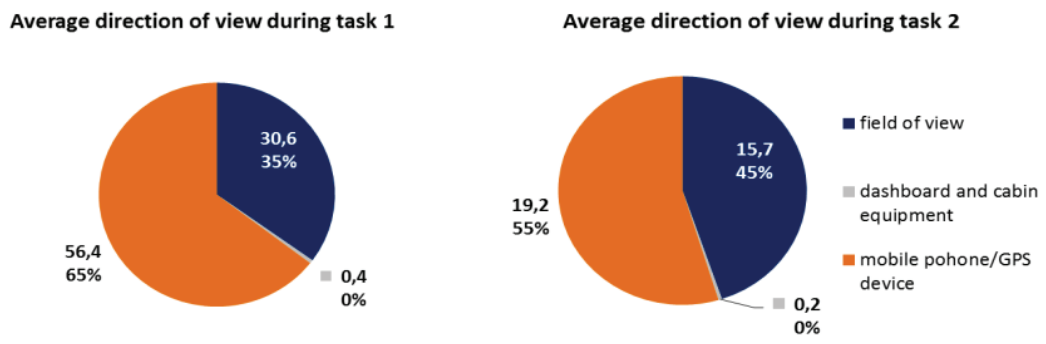

Fig. 9. Pie chart of results from eye tracking during the task 1 and 2. Source: authors

Pie charts show only specific part of the experiment, time between starting and ending the task. It's obvious, that the first task was done by average driver in 1 minute and 27.4 seconds, the second one in 31.1 seconds. Results of first task showed that drivers have given $65 \%$ of their attention to the mobile phone. When drivers have been setting the target on the GPS device, they have been looking to its touchscreen for $19.2 \mathrm{~s}$ (approximate value) and 157 seconds they were concentrated on driving.

\section{Conclusion}

The main aim of our paper was to determine the behaviour of the driver while he is driving. All tasks were done in virtually simulated environment and in real vehicle cabin. Training driving simulator SNA - 211 REN located at University Science Park of University of Žilina is a device with only few predefined simulations and also small variability of settings. It seems that it will be necessary to use different simulation device in future. One of our aims was to make sample measurement methodology and also realise measurements. The most effective method for the research of driver-vehicle interaction is combination of driving simulator and eye tracking device, which has given us the relevant results. Thanks to the simulation, it is also possible to do tasks that are not legal in real conditions.

This paper is supported by the research project "From horse-drawn railway to intermodal transport" within Visegrad Fund.

\section{References,}

1. A. Kalašová, M. Mikušová, Bezpečnost’ cestnej dopravy a dopravná psychológia, 224, (University of Žilina, Slovak Republic, 2017)

2. M. Korfant, M. Gogola, TRANSCOM 2017 - International scientific conference on sustainable, modern and safe transport 192, 433-438 (2017)

3. J. Ondruš, L. Černický, Communications: scientific letters of the University of Žilina 18, 118-123 (2016)

4. C. Hydén, The development of a method for traffic safety evaluation: The Swedish Traffic Conflicts Technique, 229, Available online: http://www.tft.lth.se/fileadmin/tft/video_in_traffic/Swedish_conflict_technique.pdf (1987)

5. M. Mikušová, TST 2011 - Modern transport telematics: 11th international conference on transport systems telematics, 70-77 (Katowice-Ustron, Poland, 2011)

6. M. Miko, J. Ondruš, Dopravné inžinierstvo 2016: International scientific conference 1, 165-174 (University of Žilina, Slovak Republic, 2016) 